\title{
Heparan sulfate proteoglycan mediates shear stress-induced endothelial gene expression in mouse embryonic stem cell- derived endothelial cells
}

\author{
Maria Nikmanesh ${ }^{1}$, Zhong-Dong Shi ${ }^{1,2}$, and John M. Tarbell, ${ }^{1 *}$ \\ ${ }^{1}$ Department of Biomedical Engineering, The City College of New York, CUNY, New York, NY \\ ${ }^{2}$ Developmental Biology Program, Memorial Sloan-Kettering Cancer Center, New York, NY
}

\begin{abstract}
It has been shown that shear stress plays a critical role in promoting endothelial cell (EC) differentiation from embryonic stem cell (ESC)-derived EC. However, the underlying mechanisms mediating shear stress effect in this process have yet to be investigated. It has been reported that the glycocalyx component heparan sulfate proteoglycan (HSPG) mediates shear stress mechanotransduction in mature EC. In this study, we investigated whether cell surface HSPG plays a role in shear stress modulation of EC phenotype. ESC-derived endothelial cells were subjected to shear stress $(5 \mathrm{dyn} / \mathrm{cm} 2)$ for 8 hours with or without heparinase III (Hep III) that digests heparan sulfate. Immunostaining showed that ESC-derived EC surfaces contain abundant HSPG, which could be cleaved by Hep III. We observed that shear stress significantly increased the expression of vascular endothelial cell-specific marker genes (vWF, VE-cadherin, PECAM-1). The effect of shear stress on expression of tight junction protein genes (ZO-1, OCLD, CLD5) was also evaluated. Shear stress increased the expression of ZO-1 and CLD5, while it didn't alter the expression of OCLD. Shear stress increased expression of vasodilatory genes (eNOS, COX-2), while it decreased the expression of the vasoconstrictive gene ET1. After reduction of HSPG with Hep III, the shear stress-induced expression of vWF, VE-cadherin, ZO-1, eNOS, and COX-2, were abolished, suggesting that shear stress-induced expression of these genes depends on HSPG. These findings indicate for the first time that HSPG is a mechanosensor mediating shear stressinduced EC differentiation from ESC-derived EC cells.
\end{abstract}

\section{Keywords}

shear stress; glycoclayx; heparan sulfate proteoglycan; mechanotransduction; embryonic stem cell; endothelial cell

\section{Introduction}

In the early stages of embryonic vasculogenesis, blood islands formed by the hemangioblasts give rise to the early vasculature needed to nourish the embryo. At this stage, fluid shear stress of blood flow is the principal mechanical force that drives further differentiation into endothelial cell (EC) phenotype (Gloe et al. 2002; Jones et al. 2006). Fully differentiated EC line the intima, the innermost part of a blood vessel, and play an important role in homeostasis as they provide a blood contacting surface resistant to clotting and a barrier to regulate the transport of solutes between blood and the underlying tissue

"Corresponding author: John M. Tarbell, PhD, Department of Biomedical Engineering, The City College of New York, CUNY, New York, USA, Tel: 1-212-650-6841, tarbell@ ccny.cuny.edu. 
(Tarbell 2010). Much effort has been expended in developing tissue-engineered vascular grafts for treatment of vascular disease. A potential source of cells for these applications are embryonic stem cells (ESC) as they are capable of differentiating into vascular cell phenotypes (Smith AG 2001).

Although there have been a number of studies that investigated the effect of growth factors on embryonic stem cell differentiation, the effect of shear stress on ESC differentiation is relatively new and only a few studies have been published on this subject. A clear in vitro demonstration of the effect of shear stress on stem cell differentiation was reported by Yamamoto et al (2003) who showed increased proliferation, differentiation, and tube formation of mouse endothelial progenitor cells (EPC) in response to shear stress. More recently, Yamamoto et al. (2005) demonstrated that shear stress induced differentiation of Flk- $1^{+}$mouse ESC into cells resembling vascular EC in vitro. McCloskey et al. (2003) showed that exposure of mouse ESC-derived EC to shear stress resulted in cytoskeleton rearrangement, as well as alignment and elongation parallel to the flow direction. Adamo et al. (2009) reported that shear stress enhanced haematopoietic development of mouse ESC. Wu et al. (2008) suggested that the combination of biochemical stimuli (growth factors) and mechanical force (shear stress) on human placenta-derived $\mathrm{EC}$ results in synergistic effects. Metallo et al. (2008) reported that human ESC-derived EC responded to shear stress by modulating gene expression and cell morphology. There have been several other shear stress studies based on an embroid body approach to initial differentiation (Ahsan and Nerem 2010; Fridley et al. 2010; Purpura et al. 2008; Sargent et al. 2010; Toh and Voldman 2011). Even though these studies have acknowledged the effect of shear stress on ESC differentiation and maturation, the underlying mechanisms of this process are unknown. Thus there is a need for hypotheses to explain the underlying mechanisms of ESC response to shear stress.

Mature endothelial cells are covered with an apical surface coating called the glycocalyx. The glycocalyx is a negatively charged mesh of membrane-bound macromolecules which include proteoglycans, glycosaminoglycans (GAGs), glycoproteins, and associated plasma proteins (Pries et al. 2000). The principal mechanical forces sensed by ECs are the shear stress of flowing blood on their apical surface, and the circumferential stress resisting blood pressure, which induces stretch in the cell body. 'Mechanotransduction' refers to the mechanisms by which these forces are transduced into biomolecular responses of the cells (Tarbell and Pahakis 2006). It has been proposed in several models that HSPGs, the major components of the endothelial glycocalyx, participate in mechanotransduction by transmitting the fluid shear stress through the HSPG core proteins into the cell where it is transduced into biochemical responses (Brower et al. 2010; Secomb et al. 2001; Shi and Tarbell 2011; Tarbell and Pahakis 2006; Thi et al. 2004; Weinbaum et al. 2007; Yao et al. 2007). It has been reported that heparinase III enzyme is specific for heparan sulfate proteoglycan and it selectively degrades the targeted glycosaminoglycan component with less than 5\% reduction of chondroitin sulfate, hyaluronic acid and sialic acid. (Tarbell and Ebong 2008). In particular, it has been demonstrated that cell surface HSPGs act as mechanosensors for mature vascular cells including endothelial cells (Florian et al. 2003; Pahakis et al. 2007), and smooth muscle cells (Ainslie et al. 2005; Shi et al. 2010; Shi et al. 2011). Furthermore, It has been reported that inhibition of heparan sulfation not only blocked differentiation of mouse ESC in the heterogeneous state but also upregulated Nanog, the pluripotency maintaining transcription factor, indicating return to a more homogenous naïve ground state (Lanner et al. 2010).

In this study, we test the hypothesis that HSPG mediates the response of ESC-derived EC to fluid shear stress during EC differentiation. 


\section{Materials and Methods}

\section{Cell culture and differentiation}

MESC obtained from ATCC were maintained in an undifferentiated state by culturing on inactivated feeder cells, using $10 \mu \mathrm{g} / \mathrm{ml}$ Mitomycin C. Primary embryonic fibroblast from CF-1 mice (MEF) also from ATCC were used for this purpose. Mouse ESC were maintained and cultured as previously described (Yamashita et al. 2000). ESCs were seeded on $0.1 \%$ gelatin coated dishes in DMEM (Gibco) containing 15\% FBS (Gibco), $10^{3} \mathrm{U} / \mathrm{ml}$ leukemia inhibitory factor (ESGRO, millipore), $1 \mathrm{mM}$ nonessential amino acid (Invitrogen), and $5 \times$ $10^{-5} \mathrm{~mol} / 1 / \beta$-mercaptoethanol (Sigma). Cells were switched to differentiation state after four days. Initiating differentiation, cells were cultured for 4-5 days in $\alpha$-minimal essential medium ( $\alpha$-MEM; cellgro), $10 \%$ FBS (cellgro), and $5 \times 10^{-5} \mathrm{M} \beta$-mercaptoethanol. CD31 ${ }^{+} /$ $\mathrm{CD} 45^{-}$cells were isolated using standard immunomagnetic techniques (MACS, Miltenyi Biotech). On day 5, the single-cell suspension from differentiated culture was incubated with CD45- FITC mAb (BD Bioscience) and CD31-PE mAb (BD Bioscience). The CD45 hematopoietic population was removed from the rest of cell population using anti-FITC beads (MACS, Miltenyi Biotech), and LD depletion columns (MACS, Miltenyi Biotech). Next, the CD45 ${ }^{-}$cell fraction was labeled with anti-PE beads (MACS, Miltenyi Biotech). Finally, $\mathrm{CD} 31^{+}$cells were isolated from the $\mathrm{CD} 45^{-}$cell fraction using LS positive selection columns (MACS, Miltenyi Biotech). The isolated mouse ESC-derived ECs (ESC-derived $\mathrm{CD} 31^{+} / \mathrm{CD} 45^{-}$cells) were plated on fibronectin coated dish (Metallo et al. 2008). After 4-5 days some individual cells with non-endothelial morphology were removed from the growing sheets using cloning cylinders (sigma).

\section{Characterization of ESC-derived endothelial cells}

Flow Cytometry-CD31 $1^{+} \mathrm{CD} 45^{-}$cells were prepared in PBS containing $0.5 \% \mathrm{BSA}$ and stained with anti- CD31PE, anti-CD45 FITC (BD Biosciences), IgG-PE and IgG-FITC the $\mathrm{PE}$ and FITC conjugated isotype control, (BD Biosciences). Samples were analyzed on a FACScalibur flow cytometer (BD Biosciences) using Flowjo software.

Immunostaining for Flk-1, Flt-1, PECAM-1, VE-cadherin, ZO-1 and CLD5-ESCderived $\mathrm{CD} 31^{+} / \mathrm{CD} 45^{-}$cells were fixed in $2 \%$ paraformaldehyde for $10 \mathrm{~min}$. The fixed cells were permeabilized for 10 min in PBS containing 0.2\% Triton X-100 (sigma), blocked for $1 \mathrm{~h}$ in PBS containing $10 \%$ bovine serum albumin (BSA) and $0.1 \%$ TritonX-100. Next, cells were incubated with primary antibodies as following: Flk-1 and Flt-1 (3:200, Alpha Diagnostic International), PECAM-1(3:200, Invitrogen), VE-cadherin (1:100, BD Bioscience), ZO-1 and CLD5 (1:200, Zymed) for 3h at room temperature or overnight at $4^{\circ} \mathrm{C}$. After washing $5 \mathrm{X}$ with PBS cells were incubated with secondary antibody, Alexa Fluor 488 (2:500, Invitrogen) for $1 \mathrm{~h}$ at room temperature. For nucleus counterstaining, cells were incubated with DAPI (1:2000, Invitrogen) or PI (1:1000, Invitrogen).

Labeling for ac-LDL-ESC-derived CD31 $/$ CD45- cells were incubated with $10 \mu \mathrm{g} / \mathrm{ml}$, Dil-labeled acetylated low density lipoprotein (Biomedical Technologies), for $4 \mathrm{~h}$ at $37^{\circ} \mathrm{C}$. Next, cells were washed with PBS, and visualized with a fluorescent microscope (Levenberg et al. 2002).

Tube formation on Matrigel—400 $\mu \mathrm{L} /$ well of growth factor-reduced Matrigel (BD Biosciences) was added to the 24-well plate and incubated at $37^{\circ} \mathrm{C}$ for $1 \mathrm{~h}$. Next ESC-derived $\mathrm{CD} 31^{+} / \mathrm{CD} 45^{-}$cells were seeded on the matrix $\left(5 \times 10^{4}\right.$ cells/well $)$ and cultured for 2 days (Metallo et al. 2008). 


\section{Shear apparatus}

The shear apparatus for this study consisted of a parallel plate flow chamber in a closed-loop system as previously described (Frangos et al. 1988). Pressure difference between upper and lower reservoirs was used to drive fluid flow through the chamber, and a peristaltic pump supplied a surplus of fluid to the upper reservoir, providing a constant flow rate to the chamber. For this purpose, ESC-derived EC were cultured at the center of a petridish for 2-3 days then a defined chamber was vacuum-sealed to the petridish and established a parallel plate flow system.

For the parallel-plate flow chamber, the wall shear stress on the cells may be calculated using the momentum balance for a Newtonian fluid. The relationship between WSS $(\tau)$, flow rate $(\mathrm{Q})$ and the chamber's geometry is defined as: $\tau=6 \mu \mathrm{Q} /\left(\mathrm{wh}^{2}\right)$ where $\mu$ is the viscosity of the perfusate, $\mathrm{w}$ is the width and $\mathrm{h}$ is the height of the flow channel. The shear stress in this study was $5 \mathrm{dyn} / \mathrm{cm}^{2}$, the calculated value from Poiseuille flow in the dorsal aorta of the mouse embryo (Adamo et al. 2009), and the exposure time was $8 \mathrm{~h}$ (time at which significant change in gene expression were noticed).

Tight junction protein localization after shear stress-To assess the effect of shear on tight junction localization and integrity ESC-derived EC were exposed $5 \mathrm{dyn} / \mathrm{cm}^{2}$ shear stress for 8hr. Then cells were immunostained for tight junction proteins: ZO-1 and CLD5 (1:200, Zymed) and the stained junctions were compared to their stained static controls. The immunostaining protocol in this part was the same as the one used in cell characterization.

Shear apparatus and heparinase III treatment-To degrade the cell surface HSPG prior to shear stress, $20 \mathrm{mU} / \mathrm{ml}$ Heparinase III (Sigma chemical) was directly added to growth media. Cells were incubated for $2 \mathrm{~h}$ at $37^{\circ} \mathrm{C}$. The flow media consisted of culture growth media with $5 \%$ FBS and $0.5 \%$ BSA supplemented either with or without $20 \mathrm{mU} / \mathrm{ml}$ Heparinase III (Sigma chemical). The applied shear was $5 \mathrm{dyn} / \mathrm{cm}^{2}$, and the exposure time was $8 \mathrm{~h}$. The enzyme concentration used in this work is sufficient to remove the HS without damaging the cells as shown for mature EC by Pahakis et al. (2007).

\section{Heparan sulfate, chondroitin sulfate, hyaluronic acid characterization and heparinase III treatment}

To assess the abundance of heparan sulfate glycosaminoglycans (HS-GAG), chondroitin sulfate glycosaminoglycans (CS-GAG), and hyaluronic acid glycosaminoglycans (HAGAG) primary antibodies: HepSS-1 (US Biological), anti-chondroitin sulfate (Sigma), and hyaluronic acid binding protein (USBiological) were used, respectively. Alexa Fluor 488 goat anti-mouse IgM (Invitrogen) was used as the secondary antibody to stain HS and CS. Anti-Biotin (Jackson Immuno) was used as the secondary antibody to stain HA. Briefly ESderived ECs were fixed with $4 \%$ paraformaldehyde (2\% PFA/0.1\% Glutaraldehyde for HA) and blocked with $4 \%$ BSA in PBS prior to incubation with primary antibodies HepSS-1(1:200; 3h), anti-CS (1:100; 3h), and HA binding protein (1:100; over night). Samples were washed three times and then incubated with secondary antibodies: anti-mouse $\operatorname{IgM}(1: 100 ; 2 h)$ for HS and CS and anti-Biotin $(1: 500 ; 2 h)$ for HA. Cells were mounted with mounting medium containing propidium iodide (PI) or DAPI (Vector Laboratories) and covered by cover slips. To cleave the cell surface HS prior to immunostaining, ESC-derived ECs were treated with Heparinase III $\left(60 \mathrm{mU} / \mathrm{ml}\right.$, Sigma chemical) and incubated at $37^{\circ} \mathrm{C}$ for $1 \mathrm{~h}$.

\section{Quantitative RT-PCR}

Total RNA from sheared and static as well as Heparinase III treated and untreated cells were harvested using the following protocol as previously described (Shi et al. 2010). ESC- 
derived EC were lysed through incubation with TRIzol LS Reagent for 3-5min (Invitrogen). To remove any insoluble materials, the cell suspension was centrifuged for $15 \mathrm{~min}$ at $13,000 \times \mathrm{g}$ and $4^{\circ} \mathrm{C}$. Chloroform was added for phase separation followed by RNA isolation using the Purelink RNA Mini Kit (Invitrogen). RNA samples were then converted to cDNA by reverse transcription (RT) reaction. Reverse transcription was performed in a total volume of $25 \mu \mathrm{l}$ containing Absolute Blue QPCR SYBR Green ROX Mix (Thermo Scientific), cDNA, and specific primer pairs. Target cDNA was amplified as follows: initial denaturing at $95^{\circ} \mathrm{C}$ for $15 \mathrm{~min}$, followed by denaturation for 45 cycles of $20 \mathrm{sec}$ at $95^{\circ} \mathrm{C}, 30$ second at $55^{\circ} \mathrm{C}$ for annealing, and 30 seconds at $72^{\circ} \mathrm{C}$ for elongation. The fluorescent data were collected at $80^{\circ} \mathrm{C}$. Primer sequences for mouse genes are listed in Table I. Gene expression was calculated using the DDCt method.

\section{Data Analysis}

All the experiments were run independent of each other. Each individual set of experiments was normalized to its own control before averaging them. Therefore, there are no error bars associated with the control group in the results figures. Results are presented as mean \pm SEM. Data were analyzed for statistical significance using a Student's t-test with a twotailed distribution, and $\mathrm{P}<0.05$ was considered statistically significant.

\section{Results}

\section{Characterization of ESC-derived endothelial cells}

We have been able to sort $\mathrm{CD} 31^{+} / \mathrm{CD} 45^{-}$cells from the mouse ESC culture. Flow cytometry analysis demonstrated that $97.1 \%$ of cells were positive for CD31 (Fig. 1A). The proportion of IgG-PE/IgG-FITC conjugated mAb control (Fig. 1B) and CD $31^{+} / \mathrm{CD} 45^{-}$cells (Fig. 1C) were measured by flow cytometry. These data reveal more than $96.7 \%$ of cells are $\mathrm{CD} 31^{+} / \mathrm{CD} 45^{-}$. In order to further characterize the ES-derived EC, cells were stained for the endothelial cell markers: Flk-1 (VEGF-2 receptor; Fig. 1D), Flt-1 (VEGF-1 receptor; Fig. 1E), PECAM-1(Fig. 1F) and VE-cadherin (Fig. 1G'). ES-derived endothelial cells were positive for all of these endothelial makers. The positive staining of nuclei for VE-cadherin in addition to the border staining indicates the embryonic stage of these immature cells which is consistent with other studies (McCloskey et al. 2006). To test the ability of ESderived EC to uptake of Dil-labeled ac-LDL, CD $31^{+} / \mathrm{CD} 45^{-}$cells were incubated with Dillabeled acetylated low density lipoprotein. There is pronounced uptake of ac-LDL by the differentiated cells, a hallmark of the endothelial phenotype (Fig $\left.1 \mathrm{H}, \mathrm{H}^{\prime}\right)$. To test the ability of ES-derived endothelial cells to form complex vascular structures in vitro, CD31 ${ }^{+} / \mathrm{CD} 45^{-}$ cells were seeded on the Matrigel matrix. After 2 days, ES-derived endothelial cells formed multidimensional tubular structures, a characteristic of endothelial behavior (Fig. 1I, I').

\section{Effect of shear stress on ESC-derived EC gene expression}

To examine the effect of laminar shear stress on expression of endothelial specific markers, ESC-derived EC were exposed to $5 \mathrm{dyn} / \mathrm{cm}^{2}$ shear stress for $8 \mathrm{~h}$. The mRNA levels were measured by RT-qRCR and shown in Figure 2.

Shear stress significantly enhanced the mRNA level of the endothelial cell markers: vWF, PECAM-1, and VE-cadherin (Fig. 2A). The expression of these genes was upregulated approximately 4-fold. We also investigated the response of tight junction molecules at the mRNA level (Fig. 2B). Our data shows ZO-1 and CLD5 mRNA levels were significantly upregulated, increasingly 3.2- and 2.4-fold respectively. Although OCLD expression increased, the increase was not statistically significant. Shear stress also altered the mRNA level of vasoregulatory genes (Fig. 2C). Shear stress enhanced the expression of the two vasodilatory genes eNOS, and COX2 by 6.2- and 6.8-fold, respectively. The expression of 
the vasoconstrictive gene, ET1, significantly decreased (30\%) upon exposure to shear stress. These results led us to test our hypothesis concerning the role of HSPG in the shear stress regulated expression of these genes in ESC-derived EC.

\section{Effect of shear stress on tight junction proteins}

To examine the effect of laminar shear stress on expression and localization of junctioal proteins, ESC-derived EC were exposed to $5 \mathrm{dyn} / \mathrm{cm}^{2}$ shear stress for $8 \mathrm{~h}$. Since we showed that shear stress significantly increased the gene expression of ZO1 and CLD5 but not OCLD, immunostaining was performed only for ZO-1 and CLD5. The immunostaining results for ZO-1 and CLD5 are shown in Figure 3. The fluorescent intensity of ZO-1 didn't increased compared to the static control. However, the pattern of distribution in ZO-1 changed from narrow border lines to a wider jagged appearance localized at the cell-cell junctions as shown for mature EC in static condition (Cancel and Tarbell 2010). Following exposure to shear stress, we observed that the fluorescent intensity of CLD5 at cell-cell borders increased, indicating an increase in CLD5 expression in these areas.

\section{ESC-derived EC surfaces contain heparan sulfate proteoglycan}

To assess the surface of ESC-derived EC for the presence of HSPG, we stained the cell surface with heparan sulfate specific antibody. As shown in Fig. 4, ESC-derived EC showed a high intensity of HS-specific fluorescence, suggesting these cell surfaces contain abundant HSPG. Treatment with heparinase III decreased the fluorescent intensity markedly, indicating that the overall expression of heparan sulfate per cell surface was significantly reduced.

\section{Heparinase III selectively degrades the targeted glycosaminoglycan}

To demonstrate that Heparinase III does not affect proteoglycans other than HSPG, we stained the surface of ESC-derived EC for chondroitin sulfate and hyaluronic acid. As shown in Fig. 5 and Fig. 6, ESC-derived EC showed moderate intensity of CS-specific and HA-specific fluorescence, suggesting these cell surfaces contain chondroitin sulfate and hyaluronic acid. Treatment with heparinase III did not change the fluorescent intensity of CS or HA, indicating that Heparinase III did not cleave either GAG component. These data demonstrate that Heparinase III is glycosaminoglycan specific and it selectively degrades the targeted GAG, as shown for mature EC (Tarbell and Ebong 2008).

\section{The role of HSPG in shear-induced ESC-derived EC gene expression}

To investigate whether HSPG serve as a mediator in shear-induced responses in ESCderived EC, we repeated our shear experiment series after cleavage of HSPG with Hep III. The ESC-derived EC were exposed to $5 \mathrm{dyn} / \mathrm{cm}^{2}$ shear stress for $8 \mathrm{~h}$. As shown in Fig. 7, Heparinase III did not affect the base line gene expression of endothelial marker genes (PECAM-1, vWF, VE-cadherin), as well as vasoregulatory genes (eNOS, ET-1, COX2), while it increased the base line gene expression of tight junction molecules (ZO-1, OCLD, and CLD5).

Upon exposure to shear stress, we observed that the shear-induced expression of vWF and VE-cadherin were abolished after removal of HSPG, while the shear-induced expression of PECAM-1 was not affected (Fig. 7A). The shear-induced expression of ZO-1 was completely abolished. The Heparinase III- induced base line elevation of ZO-1, OCLD and CLD5 were attenuated by shear force, although the effects were not statistically significant for OCLD and CLD5 (Fig. 7B). The Shear stress-induced effects on eNOS and COX2 were completely abolished, while the suppression of ET-1 gene expression induced by shear was not affected (Fig. 7C). 


\section{Discussion}

The differentiation of embryonic stem cells into desired lineages depends on the chemical environment of the "niche", and for certain lineages such as the vascular lineage that must function in a mechanical environment, the timely imposition of mechanical forces is critical. It has been reported that ESC are flow perceptive and that their proliferation and differentiation into vascular endothelial cells can be enhanced by shear stress (Wang et al. 2005; Yamamoto et al. 2005; Zeng et al. 2006). Furthermore, it has been reported that the cell surface glycocalyx mediates shear stress mechanotransduction on mature endothelial cell (Tarbell and Pahakis 2006). Important evidence that supports a major role for the glycocalyx in mechanotransduction comes from the study of Florian et al. (2003) who showed that the degradation of the glycocalyx heparan sulfate proteoglycan of bovine aortic endothelial cell in vitro completely blocked shear-induced nitric oxide (NO) production.

In the present study we show that shear stress induces the gene expression of vWF, VEcadherin, and PECAM-1 (Fig. 2A). These results are supported by other studies using stem cells and progenitor cells. For example, it has been reported that shear stress increases the expression of PECAM-1 and VE-cadherin in $\mathrm{mESC}$-derived EC at protein and gene levels (Yamamoto et al. 2005). In addition, work by Wang et al. (2005) on murine mesenchymal progenitor cells also demonstrated that laminar shear stress upregulated EC markers (PECAM-1, VE-cadherin and vWF) at gene and protein levels. Furthermore, it has been shown that shear stress increases the expression of $\mathrm{vWF}$ protein in endothelial progenitor cells (Ye et al. 2008), and vWF mRNA in HUVEC (Hough et al. 2008).

Our gene expression data indicating a significant response of ESC-derived EC to stress shear is consistent with the above studies. However, we for the first time report a role for the glycocalyx in the shear -induced response of ESC-derived EC. After removal of heparan sulfate the shear stress-induced increase of VWF and VE-cadherin were abolished (Fig. 7A). However, heparinase III didn't alter the shear induced effect on PECAM-1expression. This indicates that the shear-induced responses of vWF and VE-cadherin are dependent on HSPG, while the shear -induced effect on PECAM-1 expression is independent of HSPG.

PECAM-1 is a member of the immunoglobulin superfamily and expressed by platelets, monocytes, and some lymphocytes, and at 10-fold higher levels on mature vascular endothelial cells (Fawcett et al. 1995). It has been shown that PECAM-1 plays a key role as shear stress mechanosensor (Tzima et al. 2005), however the regulation of PECAM-1 expression under flow in vitro or in vivo remain unclear (Stevens et al. 2008; Woodfin et al. 2007).

We report that shear stress significantly increases the gene expression of ZO-1, and CLD5, while there is no significant change in expression of OCLD (Fig. 2B). Interestingly, we couldn't find any previous studies of tight junction components of stem cells or progenitor cells. In adult cells there are contradictory results regarding shear effects on these junctional molecules. DeMaio et al. (2001) reported that exposure of BAECs to shear stress reduced OCLD expression at the mRNA and protein levels. No change in ZO-1 expression was observed. However, Conklin et al. (2002) has reported that low shear stress compared to physiological levels in porcine carotid arteries, downregulated the expression of OCLD at mRNA and protein levels. Karamanian (2009) showed that subjecting HUVECS to disturbed flow resulted in inhibition of CLD5 expression at protein level compared to laminar flow. On the other hand, Dekker et al. (2002) reported exposure of HUVECs to laminar shear stress downregulates gene expression of CLD5.

The difference in the conclusions of the above studies could be the result of different cell types and shear models. Furthermore, the tight junction components of adult cells might not 
be a valid reference to be used for comparing with the tight junction components of embryonic cells. It has been reported that some tight junction proteins such as ZO-1 are found at the adherens junctions during early stages of junction formation and later when junctions become stable they move to tight junctions and become concentrated at those sits (Dejana 2004).

It has been shown that there are differences between mature EC responses to shear and ESCderived EC responses to shear stress. For example vWF, eNOS, COX2 are upregulated in both mature ECs and ESC-ECs. However, junctional proteins which are an important part of the integrity and functionality of endothelial cells behave differently. It has been shown that shear stress does not affect ZO-1 expression in mature endothelial cells (Demaio et al 2001, Berardi et al. 2009) and it down regulates expression of OCLD and CLD5 (Dekker et al. 2002, Demaio et al 2001). At the gene level we have shown that the expression of ZO-1and CLD5 are upregulated (Figure 2) and at the protein level we showed an increase in expression of CLD5 and a change in the morphology of ZO-1 (Figure 3). These results not only show that junctional proteins change in the process of differentiation, but also show the important role of shear stress in this process.

The most apical junctions, the tight junctions (Michel and Curry 1999), very often mix with adherens junctions all the way along the intercellular cleft (Dejana 2004). After removal of HSPG we observed an increased in base line expression of ZO-1, OCLD, and CLD5 in static controls samples compared to their untreated counterparts (Fig. 7B). The response of ZO-1 to the enzyme treatment was more robust (with smaller standard deviation) compared to OCLD and CLD5 responses (with larger standard deviations). Although the nature of this behavior is yet to be elucidated, the location of these tight junction molecules might provide some clues. It is possible that removal of HSPG at the apical junction triggers and disturbs gene expression of some transmembrane components of the tight junction, in particular occludin and claudin5 (which directly contact the glycocalyx), as well as affecting the cytoplasmic components of tight junction, such as ZO-1 (which doesn't contact the glycocalyx), with less impact. In addition, the response of ZO-1 to shear stress before and after disruption of glycocalyx is closer to the VE-cadherin response than the OCLD and CLD5 responses which further strengthens the idea that ZO-1 may localize at the adherens junction during the early stages of junction formation.

Our observation of upregulation of eNOS and COX2 and downregulation of ET-1 upon exposure to shear stress (Fig. 2C) is consistent with that seen in mESC-derived EC (Toda et al. 2008) and in hESC-derived EC (Metallo et al. 2008) both at mRNA levels. These results confirm that the shear stress is critical to enhance the expression of vasoregulatory genes.

After cleavage of HSPG the shear stress-induced effects on the two vasodilatory genes, eNOs and COX2 were abolished. However removal of HSPG didn't alter the shear-induced response of ET-1 (Fig. 7C). This indicates that shear stress-induced responses of eNOS and $\mathrm{COX} 2$ are dependent on HSPG, while the shear stress-induced effect on ET-1expression is independent of HSPG.

It has been reported that ET- 1 expression in endothelial cells is dependent on TGF- $\beta$ (Castanares et al. 2007) and inhibition of TGF- $\beta$ enhances growth and integrity of human and mouse embryonic stem cell-derived endothelial cells, respectively (James et al. 2010; Watabe et al. 2003). Furthermore, Wang et al. (2008) showed that applied shear stress on mouse embryonic mesenchymal progenitor cells abolished TGF- $\beta$ signaling through downregulation of TGF- $\beta 1$. Therefore whether TGF- $\beta$ has any role in shear-induced EC differentiation and ET1 down-regulation needs to be investigated. 
Recent studies by different groups have confirmed the significant influence of shear stress on differentiation of ESC to vascular EC. The current study presents the first evidence that HSPG, as a mechanosensor, can contribute to shear-induced regulation of ESC-derived EC. The outcome of this study provides a deeper understanding of the underlying mechanism by which shear stress promotes ESC-derived EC differentiation, and may provide clues for enhancing the maturation of ESC-derived ECs. This may ultimately help us to produce more functional $\mathrm{EC}$ for applications in vascular repair and tissue engineering. It is apparent that the HSPG component of the glycocalyx plays an important role in shear-induced EC differentiation. It will be of great interest to further study what other components of the glycocalyx play a role in differentiation of ESC into EC. It will also be interesting to investigate the shear -induced mechanisms for HSPG-independent genes.

\section{Acknowledgments}

Training in stem cell culture was provided by Dr. Tabassum Ahsan in the laboratory of Dr. Robert M. Nerem at Georgia Institute of Technology; Consultation on cell sorting for endothelial cells was provided by Dr. Igor I. Slukvin at University of Wisconsin - Madison. This work was supported by NIH/NHLBI 1 RO1 HL086543 and State of New York Department of Health (NYSTEM).

\section{References}

Adamo L, Naveiras O, Wenzel PL, McKinney-Freeman S, Mack PJ, Gracia-Sancho J, Suchy-Dicey A, Yoshimoto M, Lensch MW, Yoder MC, et al. Biomechanical forces promote embryonic haematopoiesis. Nature. 2009; 459(7250):1131-5. [PubMed: 19440194]

Ahsan T, Nerem RM. Fluid shear stress promotes an endothelial-like phenotype during the early differentiation of embryonic stem cells. Tissue Eng Part A. 2010; 16(11):3547-53. [PubMed: 20666609]

Ainslie KM, Garanich JS, Dull RO, Tarbell JM. Vascular smooth muscle cell glycocalyx influences shear stress-mediated contractile response. J Appl Physiol. 2005; 98(1):242-9. [PubMed: 15322072]

Brower JB, Targovnik JH, Caplan MR, Massia SP. High glucose-mediated loss of cell surface heparan sulfate proteoglycan impairs the endothelial shear stress response. Cytoskeleton (Hoboken). 2010; 67(3):135-41. [PubMed: 20217676]

Cancel LM, Tarbell JM. The role of apoptosis in LDL transport through cultured endothelial cell monolayers. Atherosclerosis. 2010; 208(2):335-41. [PubMed: 19709659]

Castanares C, Redondo-Horcajo M, Magan-Marchal N, ten Dijke P, Lamas S, Rodriguez-Pascual F. Signaling by ALK5 mediates TGF-beta-induced ET-1 expression in endothelial cells: a role for migration and proliferation. J Cell Sci. 2007; 120(Pt 7):1256-66. [PubMed: 17376964]

Conklin BS, Zhong DS, Zhao W, Lin PH, Chen C. Shear stress regulates occludin and VEGF expression in porcine arterial endothelial cells. J Surg Res. 2002; 102(1):13-21. [PubMed: 11792146]

Dejana E. Endothelial cell-cell junctions: happy together. Nat Rev Mol Cell Biol. 2004; 5(4):261-70. [PubMed: 15071551]

Dekker RJ, van Soest S, Fontijn RD, Salamanca S, de Groot PG, VanBavel E, Pannekoek H, Horrevoets AJ. Prolonged fluid shear stress induces a distinct set of endothelial cell genes, most specifically lung Kruppel-like factor (KLF2). Blood. 2002; 100(5):1689-98. [PubMed: 12176889]

DeMaio L, Chang YS, Gardner TW, Tarbell JM, Antonetti DA. Shear stress regulates occludin content and phosphorylation. Am J Physiol Heart Circ Physiol. 2001; 281:105-13.

Fawcett J, Buckley C, Holness CL, Bird IN, Spragg JH, Saunders J, Harris A, Simmons DL. Mapping the homotypic binding sites in CD31 and the role of CD31 adhesion in the formation of interendothelial cell contacts. J Cell Biol. 1995; 128(6):1229-41. [PubMed: 7534767]

Florian JA, Kosky JR, Ainslie K, Pang Z, Dull RO, Tarbell JM. Heparan sulfate proteoglycan is a mechanosensor on endothelial cells. Circ Res. 2003; 93(10):e136-42. [PubMed: 14563712] 
Frangos JA, McIntire LV, Eskin SG. Shear stress induced stimulation of mammalian cell metabolism. Biotechnol Bioeng. 1988; 32(8):1053-60. [PubMed: 18587822]

Fridley KM, Fernandez I, Li MT, Kettlewell RB, Roy K. Unique differentiation profile of mouse embryonic stem cells in rotary and stirred tank bioreactors. Tissue Eng Part A. 2010; 16(11):328598. [PubMed: 20528675]

Gloe T, Sohn HY, Meininger GA, Pohl U. Shear stress-induced release of basic fibroblast growth factor from endothelial cells is mediated by matrix interaction via integrin alpha(v)beta3. J Biol Chem. 2002; 277(26):23453-8. [PubMed: 11976347]

Hough C, Cameron CL, Notley CR, Brown C, O’Brien L, Keightley AM, Berber E, Lillicrap D. Influence of a GT repeat element on shear stress responsiveness of the VWF gene promoter. J Thromb Haemost. 2008; 6(7):1183-90. [PubMed: 18485092]

James D, Nam HS, Seandel M, Nolan D, Janovitz T, Tomishima M, Studer L, Lee G, Lyden D, Benezra R, et al. Expansion and maintenance of human embryonic stem cell-derived endothelial cells by TGFbeta inhibition is Id1 dependent. Nat Biotechnol. 2010; 28(2):161-6. [PubMed: 20081865]

Jones EA, le Noble F, Eichmann A. What determines blood vessel structure? Genetic prespecification vs. hemodynamics. Physiology (Bethesda). 2006; 21:388-95. [PubMed: 17119151]

Karamanian, AA. Role of claudin-5 and hemodynamics in endothelial permeability and susceptibility to atherosclerosis. Philadelphia: University of Pennsylvania; 2009.

Lanner F, Lee KL, Sohl M, Holmborn K, Yang H, Wilbertz J, Poellinger L, Rossant J, Farnebo F. Heparan sulfation-dependent fibroblast growth factor signaling maintains embryonic stem cells primed for differentiation in a heterogeneous state. Stem Cells. 2010; 28(2):191-200. [PubMed: 19937756]

Levenberg S, Golub JS, Amit M, Itskovitz-Eldor J, Langer R. Endothelial cells derived from human embryonic stem cells. PNAS. 2002; 99(7):4391-4396. [PubMed: 11917100]

McCloskey KE, Lyons I, Rao R, Stice SL, Nerem RM. Purified and Proliferating Endothelial Cells Derived and Expanded In Vitro from Embryonic Stem Cells. Endothelium. 2003; 10:329-336. [PubMed: 14741848]

McCloskey KE, Smith DA, Jo H, Nerem RM. Embryonic Stem Cell-Derived Endothelial Cells May Lack Complete Functional Maturation in vitro. J Vasc Res. 2006; 43:411-421. Published online: July 28, 2006. [PubMed: 16877873]

Metallo CM, Vodyanik MA, de Pablo JJ, Slukvin, Palecek SP. The response of human embryonic stem cell-derived endothelial cells to shear stress. Biotechnol Bioeng. 2008; 100(4):830-7. [PubMed: 18306423]

Michel CC, Curry FE. Microvascular permeability. Physiol Rev. 1999; 79(3):703-61. [PubMed: 10390517]

Pahakis MY, Kosky JR, Dull RO, Tarbell JM. The role of endothelial glycocalyx components in mechanotransduction of fluid shear stress. Biochem Biophys Res Commun. 2007; 355(1):228-33. [PubMed: 17291452]

Pries AR, Secomb TW, Gaehtgens P. The endothelial surface layer. Pflugers Arch. 2000; 440(5):65366. [PubMed: 11007304]

Purpura KA, George SH, Dang SM, Choi K, Nagy A, Zandstra PW. Soluble Flt-1 regulates Flk-1 activation to control hematopoietic and endothelial development in an oxygen-responsive manner. Stem Cells. 2008; 26(11):2832-42. [PubMed: 18772315]

Sargent CY, Berguig GY, Kinney MA, Hiatt LA, Carpenedo RL, Berson RE, McDevitt TC. Hydrodynamic modulation of embryonic stem cell differentiation by rotary orbital suspension culture. Biotechnol Bioeng. 2010; 105(3):611-26. [PubMed: 19816980]

Secomb TW, Hsu R, Pries AR. Effect of the endothelial surface layer on transmission of fluid shear stress to endothelial cells. Biorheology. 2001; 38(2-3):143-50. [PubMed: 11381171]

Shi ZD, Abraham G, Tarbell JM. Shear stress modulation of smooth muscle cell marker genes in 2-D and 3-D depends on mechanotransduction by heparan sulfate proteoglycans and ERK1/2. PLoS One. 2010; 5(8):e12196. [PubMed: 20808940]

Shi ZD, Tarbell JM. Fluid Flow Mechanotransduction in Vascular Smooth Muscle Cells and Fibroblasts. Ann Biomed Eng. 2011; 39(6):1608-19. [PubMed: 21479754] 
Shi ZD, Wang H, Tarbell JM. Heparan sulfate proteoglycans mediate interstitial flow mechanotransduction regulating MMP-13 expression and cell motility via FAK-ERK in 3D collagen. PLoS One. 2011; 6(1):e15956. [PubMed: 21246051]

Smith AG. Embryo-derived stem cells: Of mice and men. Annu Rev Cell Dev Biol. 2001; 17:435-62. [PubMed: 11687496]

Stevens HY, Melchior B, Bell KS, Yun S, Yeh JC, Frangos JA. PECAM-1 is a critical mediator of atherosclerosis. Dis Model Mech. 2008; 1(2-3):175-81. discussion 179. [PubMed: 19048083]

Tarbell JM. Shear stress and the endothelial transport barrier. Cardiovasc Res. 2010; 87(2):320-30. [PubMed: 20543206]

Tarbell JM, Ebong EE. The endothelial glycocalyx: a mechano-sensor and -transducer. Sci Signal. 2008; 1(40):pt8. [PubMed: 18840877]

Tarbell JM, Pahakis MY. Mechanotransduction and the glycocalyx. J Intern Med. 2006; 259(4):339_ 50. [PubMed: 16594902]

Thi MM, Tarbell JM, Weinbaum S, Spray DC. The role of the glycocalyx in reorganization of the actin cytoskeleton under fluid shear stress: a "bumper-car" model. Proc Natl Acad Sci U S A. 2004; 101(47):16483-8. [PubMed: 15545600]

Toda M, Yamamoto K, Shimizu N, Obi S, Kumagaya S, Igarashi T, Kamiya A, Ando J. Differential gene responses in endothelial cells exposed to a combination of shear stress and cyclic stretch. J Biotechnol. 2008; 133(2):239-44. [PubMed: 17850909]

Toh YC, Voldman J. Fluid shear stress primes mouse embryonic stem cells for differentiation in a selfrenewing environment via heparan sulfate proteoglycans transduction. FASEB J. 2011; 25(4): 1208-17. [PubMed: 21183594]

Tzima E, Irani-Tehrani M, Kiosses WB, Dejana E, Schultz DA, Engelhardt B, Cao G, DeLisser H, Schwartz MA. A mechanosensory complex that mediates the endothelial cell response to fluid shear stress. Nature. 2005; 437(7057):426-31. [PubMed: 16163360]

Wang H, Riha GM, Yan S, Li M, Chai H, Yang H, Yao QCC. Shear Stress Induces Endothelial Differentiation From a Murine Embryonic Mesenchymal Progenitor Cell Line. Arterioscler Thromb Vasc Biol. 2005; 25:1817-1823. [PubMed: 15994439]

Wang H, Li M, Lin PH, Yao Q, Chen C. Fluid shear stress regulates the expression of TGF-beta1 and its signaling molecules in mouse embryo mesenchymal progenitor cells. J Surg Res. 2008; 150(2): 266-70. [PubMed: 18547588]

Wang H, Riha GM, Yan S, Li M, Chai H, Yang H, Yao Q, Chen C. Shear stress induces endothelial differentiation from a murine embryonic mesenchymal progenitor cell line. Arterioscler Thromb Vasc Biol. 2005; 25(9):1817-23. [PubMed: 15994439]

Watabe T, Nishihara A, Mishima K, Yamashita J, Shimizu K, Miyazawa K, Nishikawa S, Miyazono K. TGF-beta receptor kinase inhibitor enhances growth and integrity of embryonic stem cellderived endothelial cells. J Cell Biol. 2003; 163(6):1303-11. [PubMed: 14676305]

Weinbaum S, Tarbell JM, Damiano ER. The structure and function of the endothelial glycocalyx layer. Annu Rev Biomed Eng. 2007; 9:121-67. [PubMed: 17373886]

Woodfin A, Voisin MB, Nourshargh S. PECAM-1: a multi-functional molecule in inflammation and vascular biology. Arterioscler Thromb Vasc Biol. 2007; 27(12):2514-23. [PubMed: 17872453]

Wu CC, Chao YC, Chen CN, Chien S, Chen YC, Chien CC, Chiu JJ, Linju Yen B. Synergism of biochemical and mechanical stimuli in the differentiation of human placenta-derived multipotent cells into endothelial cells. J Biomech. 2008; 41(4):813-21. [PubMed: 18190919]

Yamamoto K, Sokabe T, Watabe T, Miyazono K, Yamashita JK, Obi S, Ohura N, Matsushita A, Kamiya A, Ando J. Fluid shear stress induces differentiation of Flk-1-positive embryonic stem cells into vascular endothelial cells in vitro. Am J Physiol Heart Circ Physiol. 2005; 288:H1915H1924. [PubMed: 15576436]

Yamamoto K, Takahashi T, Asahara T, Ohura N, Sokabe T, Kamiya A, Ando J. Proliferation, differentiation, and tube formation by endothelial progenitor cells in response to shear stress. $\mathbf{J}$ Appl Physiol. 2003; 95:2081-2088. [PubMed: 12857765]

Yamashita J, Itoh H, Hirashima M, Ogawa M, Nishikawa S, Yurugi T, Naito M, Nakao K. Flk1positive cells derived from embryonic stem cells serve as vascular progenitors. nature. 2000; 408(6808):92-6. [PubMed: 11081514] 
Yao Y, Rabodzey A, Dewey CF Jr. Glycocalyx modulates the motility and proliferative response of vascular endothelium to fluid shear stress. Am J Physiol Heart Circ Physiol. 2007; 293(2):H102330. [PubMed: 17468337]

Ye C, Bai L, Yan ZQ, Wang YH, Jiang ZL. Shear stress and vascular smooth muscle cells promote endothelial differentiation of endothelial progenitor cells via activation of Akt. Clin Biomech (Bristol, Avon). 2008; 23(Suppl 1):S118-24.

Zeng L, Xiao Q, Margariti A, Zhang Z, Zampetaki A, Patel S, Capogrossi MC, Hu Y, Xu Q. HDAC3 is crucial in shear- and VEGF-induced stem cell differentiation toward endothelial cells. J Cell Biol. 2006; 174(7):1059-69. [PubMed: 16982804] 

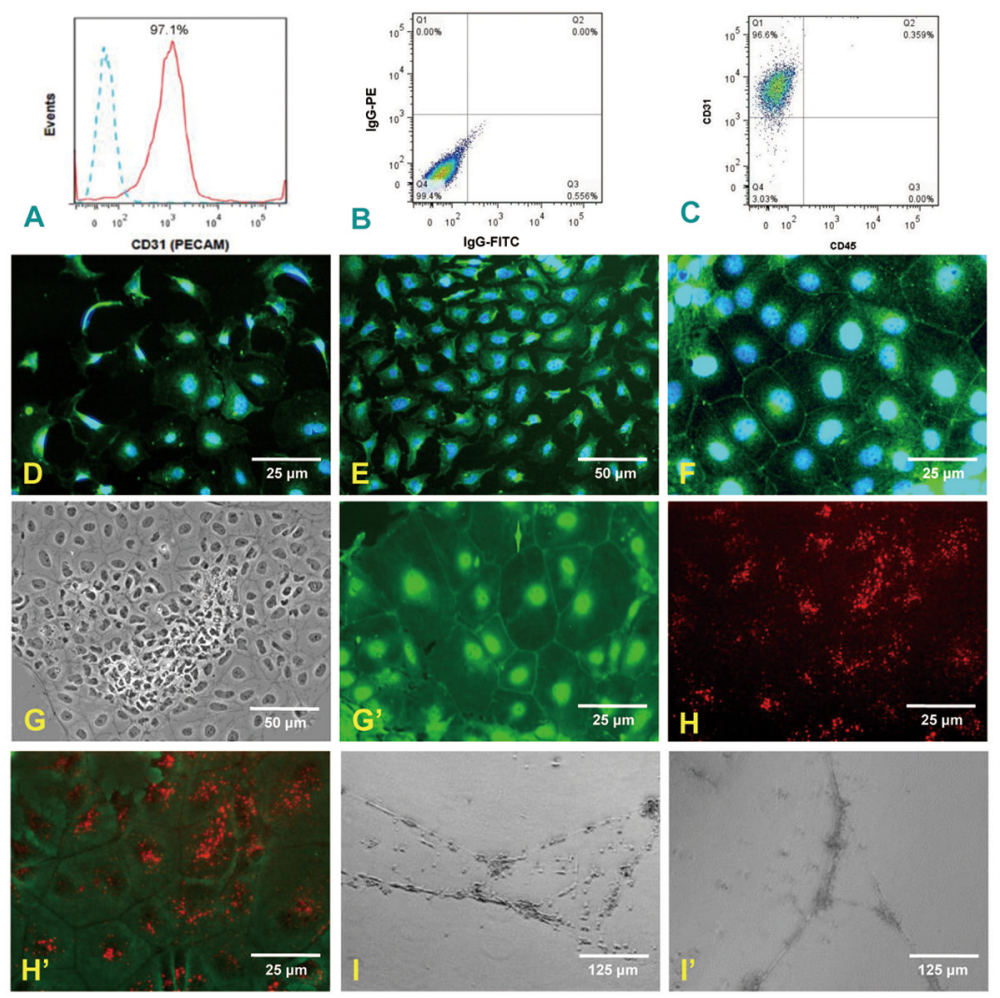

Fig. 1.

Evidence that ESC-derived ECs (CD31 ${ }^{+} / \mathrm{CD} 45^{-}$cells) display endothelial phenotype characteristics. Panel (A) shows flow cytometry analysis of ESC-derived endothelial cells stained for CD31 PE (solid red) and isotype control (dashed lines) indicating that $97.1 \%$ of cells are positive for CD31. Panels (B) and (C) represent flow cytometry analysis of IgG-PE/ IgG-FITC isotypes conjugated control and $\mathrm{CD} 31^{+} / \mathrm{CD} 45^{-}$cells respectively. Percentage values are shown for respective quadrants. Panels (D) and (E) show the expression of Flk-1 (VEGR2) and Flt-1 (VEGR1) on ESC-derived ECs respectively. Panel (F) shows the expression of PECAM-1. Panel (G) shows clearly a colony of CD $31^{+} / \mathrm{CD} 45^{-}$cells where they become more differentiated from the center toward the periphery, taking on the cobblestone morphology of EC in static culture. Panel $\left(\mathrm{G}^{\prime}\right)$ shows a group of cells where the expression of VE-cadherin at the cell borders is enhanced. Panel $\mathrm{H} / \mathrm{H}^{\prime}$ displays the uptake of acetylated LDL by $\mathrm{CD} 31^{+} / \mathrm{CD} 45^{-}$cells. (H) shows dominant red staining of ac-LDL over a field of $\mathrm{CD} 31^{+} / \mathrm{CD} 45^{-}$cells. $\left(\mathrm{H}^{\prime}\right)$ superimposes the ac-LDL staining on the cell outlines. ESC-derived ECs were plated onto growth factor-reduced Matrigel and cultured for $24 \mathrm{~h}$ (I). On day 2, ES-derived endothelial cells formed 3-dimensional tubes, a capillary-like endothelial structure $\left(\mathrm{I}^{\prime}\right)$. 

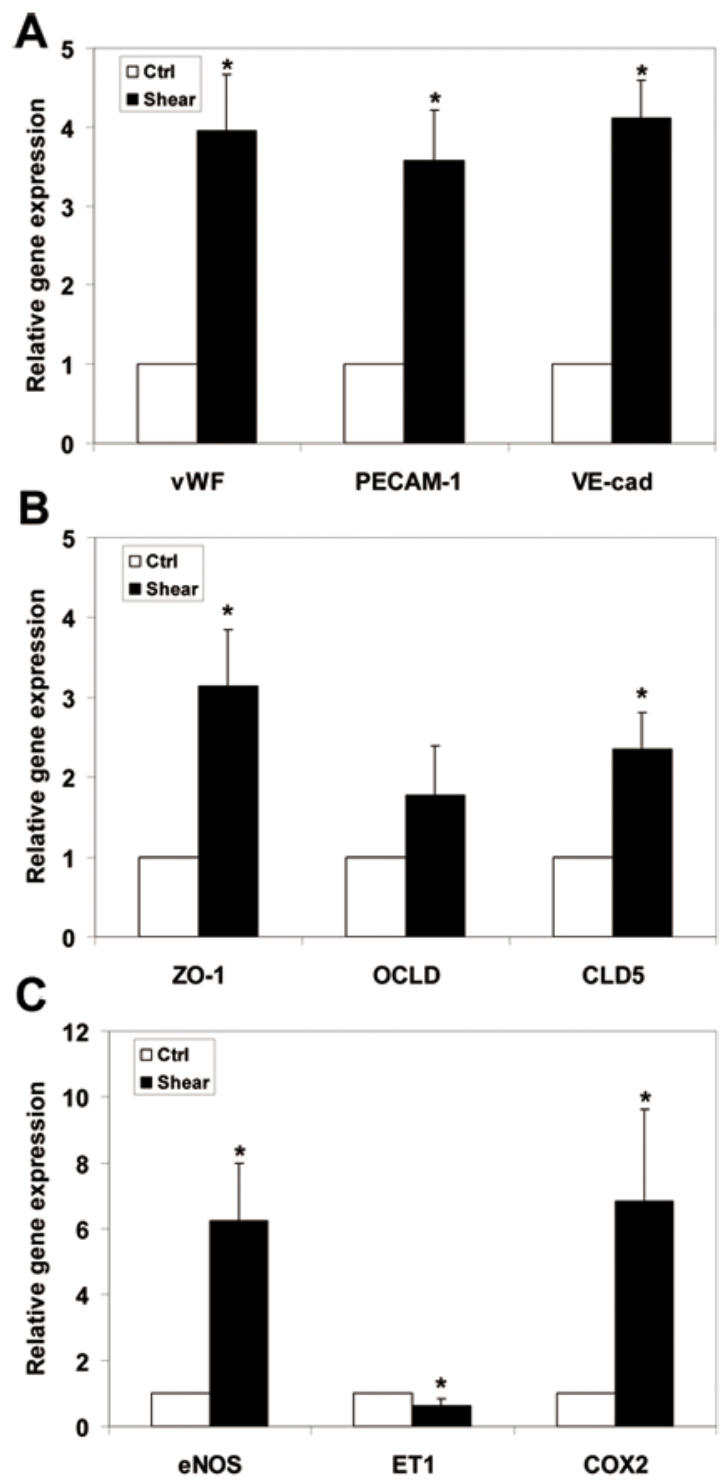

Fig. 2.

ESC-derived EC gene response after exposure to shear stress ( $5 \mathrm{dyn} / \mathrm{cm}^{2}$ for $8 \mathrm{~h}$ ). Relative gene expression (gene/GAPDH) was measured by qPCR and normalized to its own static control case. mRNA level of endothelial cells markers: vWF, PECAM-1, and VE-cadherin were significantly enhanced (A). From the tight junction group, the mRNA levels of ZO-1 and CLD5 were significantly upreguated; no significant change in expression of OCLD was observed (B). Shear stress significantly modulated the expression of vasoregulatory genes. The mRNA expression of eNOS and COX2 were significantly increased, while the expression of ET-1 was significantly decreased $(\mathrm{C})$. ${ }^{*} \mathrm{P}<0.05$ compared to unsheared control $(n=3-7)$. 

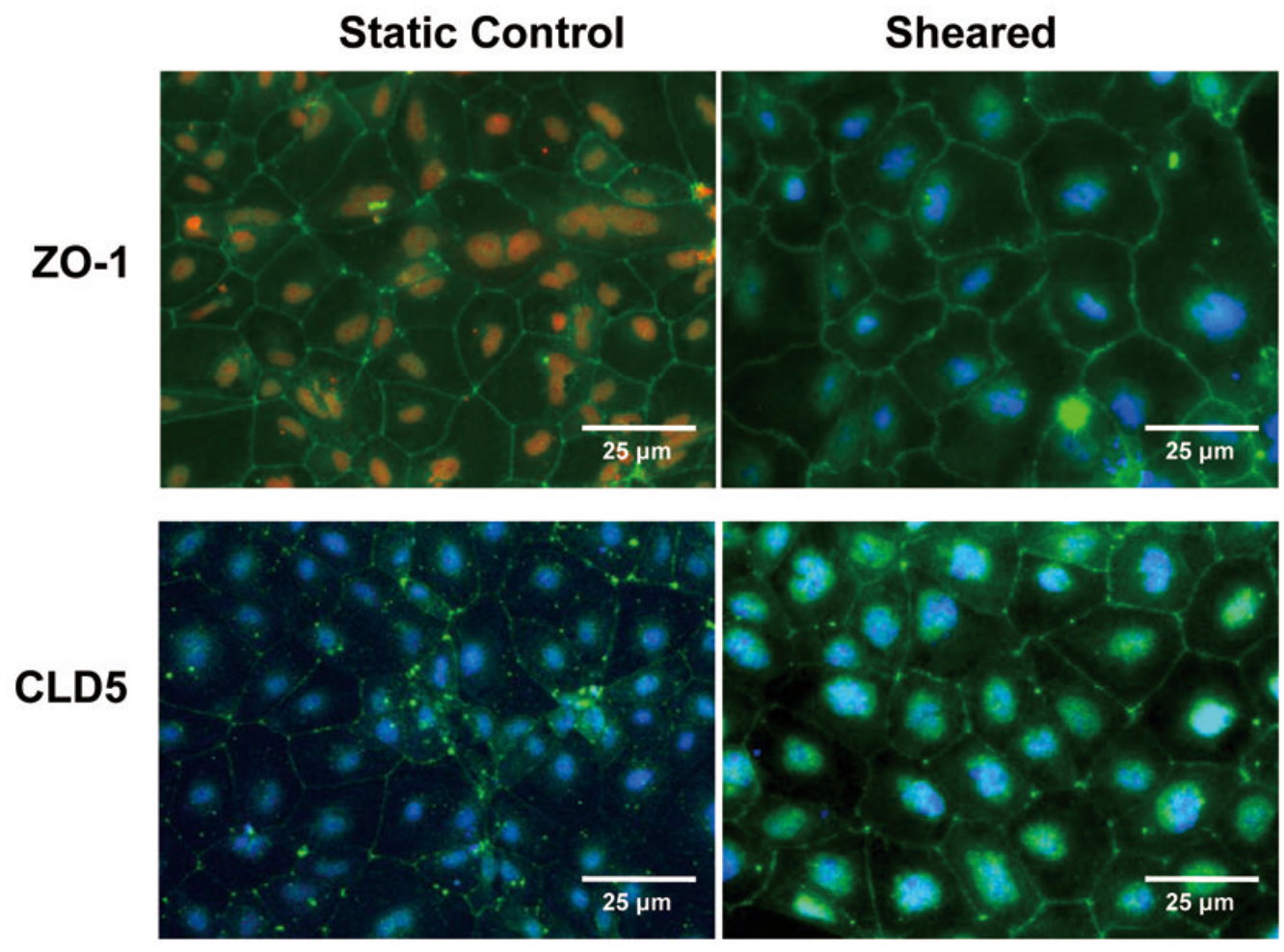

Fig. 3.

Immunofluorescence staining for ZO-1 and CLD5 in ESC-derived ECs before and after exposure to shear stress ( $5 \mathrm{dyn} / \mathrm{cm}^{2}$ for $8 \mathrm{~h}$ ). (Top panels) show that shear stress changed the distribution of ZO-1 from narrow border lines to a wider jagged pattern localized at the cellcell junctions. (Lower panels) show shear stress increased expression of CLD5 at cell borders. 

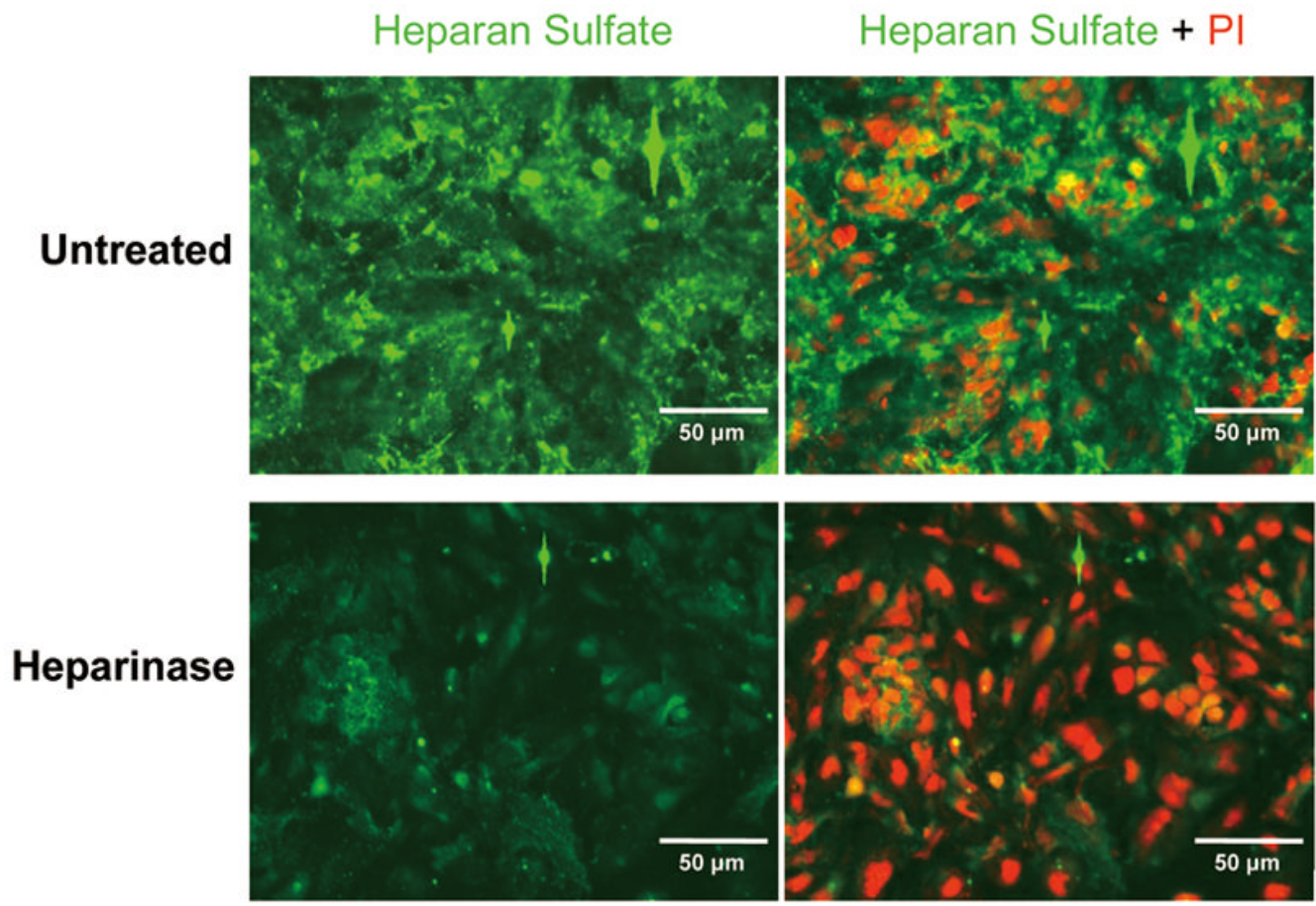

Fig. 4.

Immunofluorescence staining for HSPG in ESC-derived ECs before and after treatment with heparinase III. (Top panels) show that the surfaces of untreated ESC-derived ECs contain HSPG. Treatment with heparinase III significantly reduced expression of HSPG (Lower panels). 


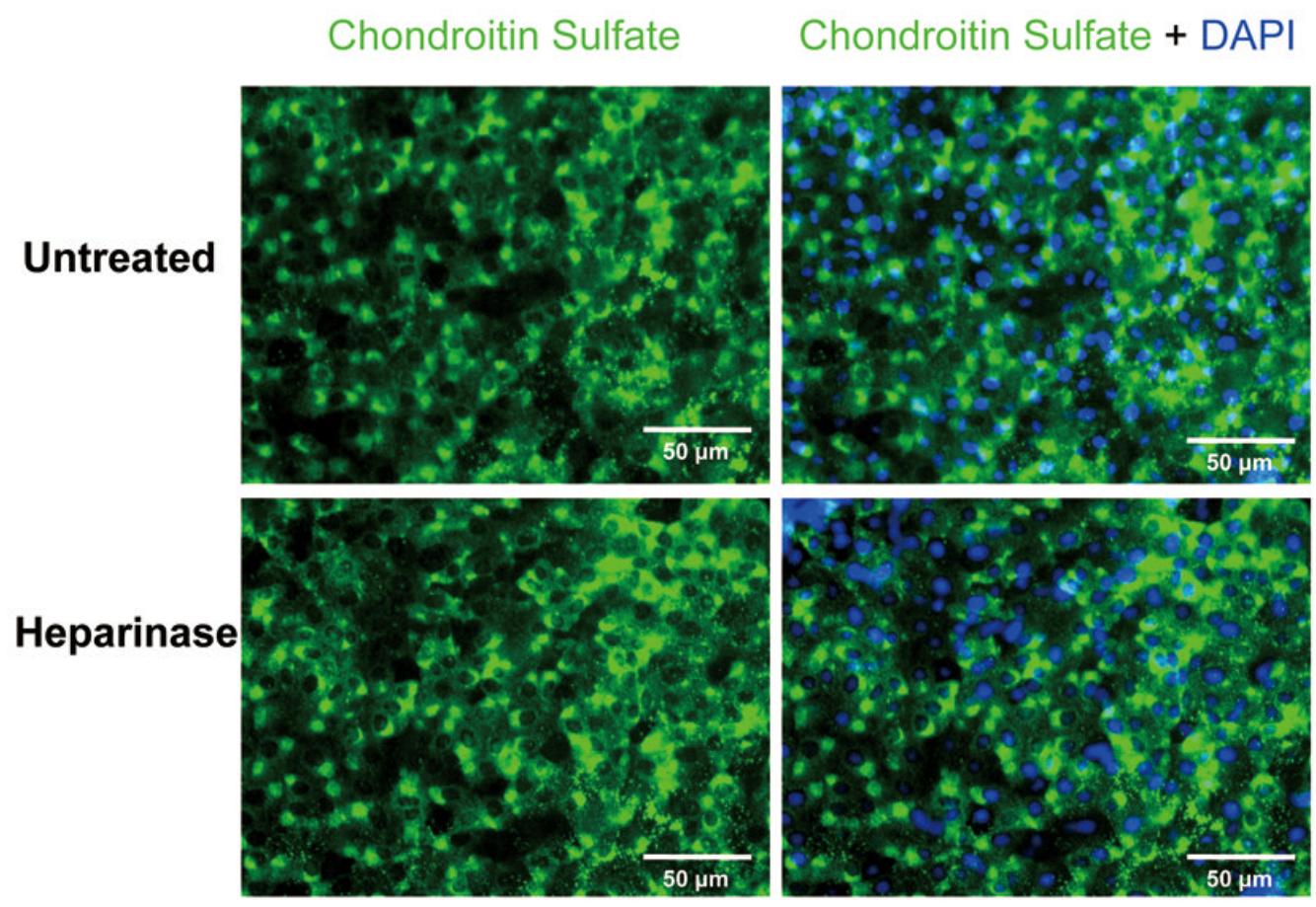

Fig. 5.

Immunofluorescence staining for CSPG in ESC-derived ECs before and after treatment with heparinase III. (Top panels) show that the surfaces of untreated ESC-derived ECs contain CSPG. Treatment with heparinase III did not change the intensity of CSPG fluorescence (Lower panels). 


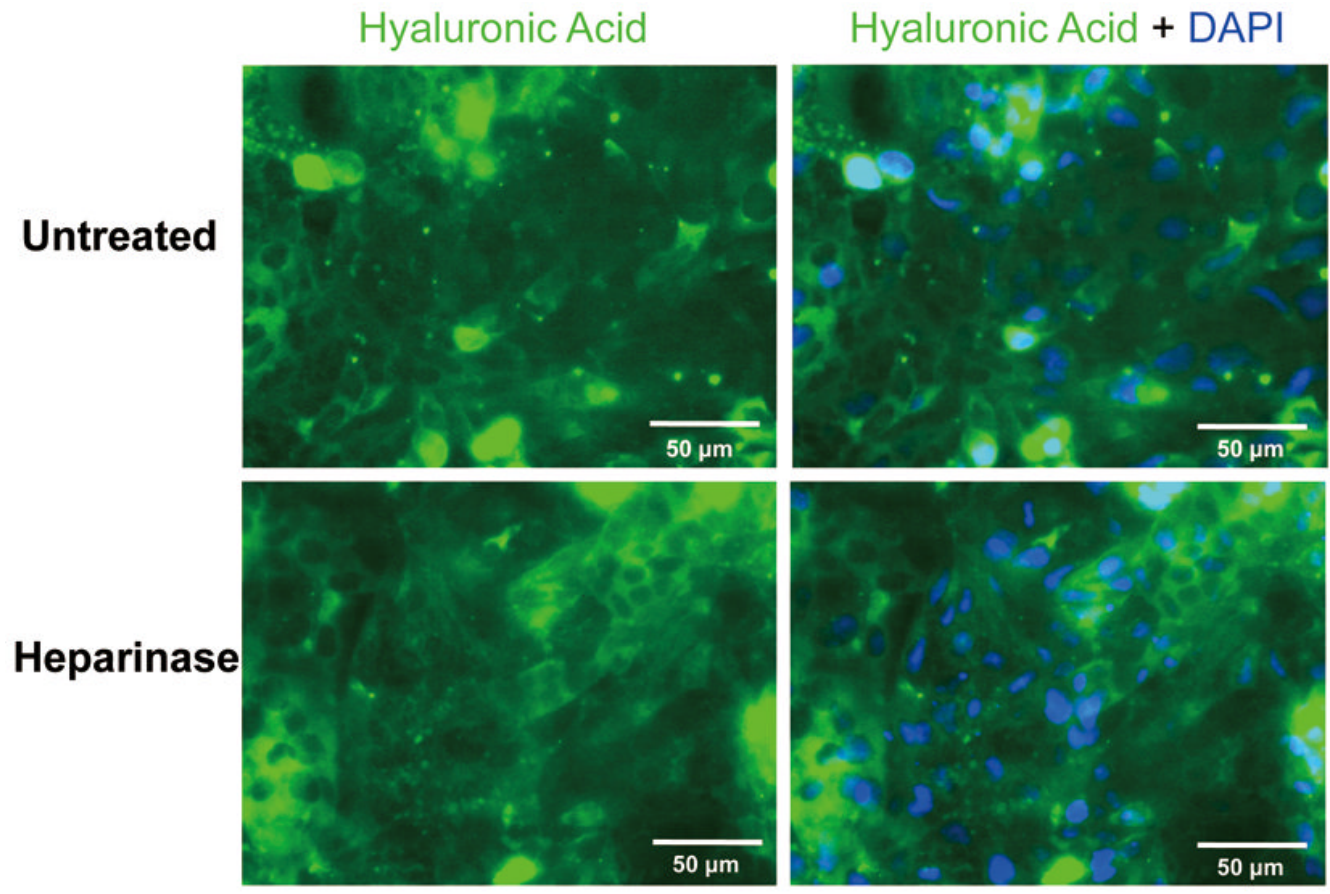

Fig. 6.

Immunofluorescence staining for HA in ESC-derived ECs before and after treatment with heparinase III. (Top panels) show that the surfaces of untreated ESC-derived ECs contain HA. Treatment with heparinase III did not change the intensity of HA fluorescence (Lower panels). 

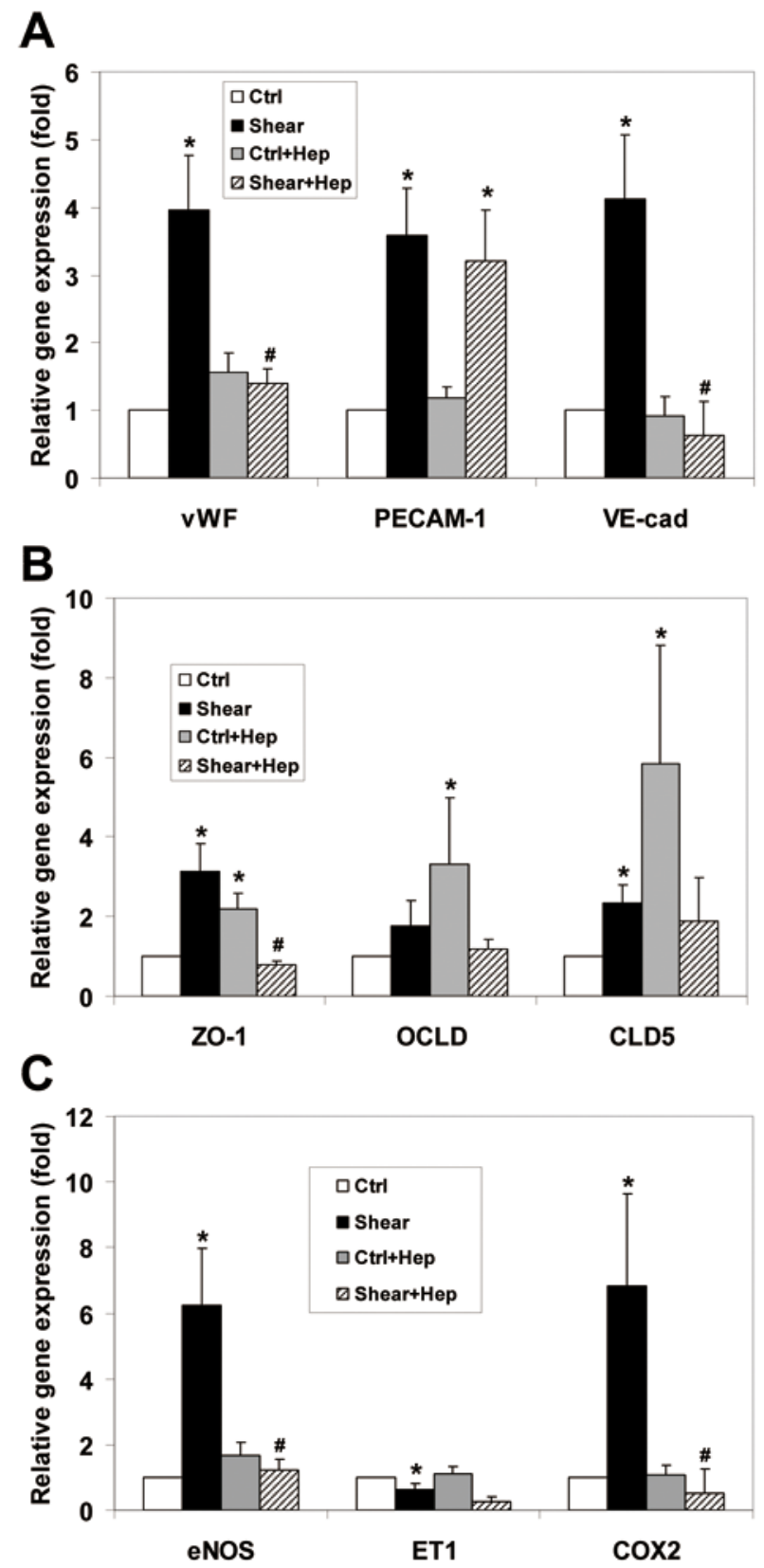

Fig. 7.

ESC-derived EC gene response to shear stress $\left(5 \mathrm{dyn} / \mathrm{cm}^{2}\right.$ for $\left.8 \mathrm{~h}\right)$ after treatment with heparinase III $(20 \mathrm{mU} / \mathrm{ml})$. Relative gene expression (gene/GAPDH) was measured by qPCR and normalized to its own static control case prior to enzyme treatment. Heparinase III did not affect the base line gene expression of endothelial marker genes and vasoregulatory genes, while it increased the base line gene expression of tight junction molecules compared to their untreated counterparts. The Shear-induced expression of vWF and VE-cadherin were completely inhibited after removal of HSPG, while the shear-induced expression of PECAM-1 was not affected (A). The Shear-induced expression of ZO-1 was completely abolished while there was no significant decrease in OCLD and CLD5 expression with respect to their Hep treated sheared cases, as well as, untreated static control cases (B). The Shear stress-induced effect on eNOS and COX2 were completely abolished, 
while the suppression of ET-1 gene expression induced by shear was not affected compared to its untreated counterpart $(\mathrm{C}) .{ }^{*} \mathrm{P}<0.05$ compared to unsheared control (ctrl); $\# \mathrm{P}<0.05$ compared to Hep untreated sheared (shear) $(n=3-7)$. 


\section{Table I}

Primer sequences for mouse genes.

\begin{tabular}{|l|l|l|l|l|}
\hline Gene & Accession NO. & Forward primer $\left(\mathbf{5}^{\prime}\right.$ to 3') & Reverse primer (5' to 3') & Reference \\
\hline vWF & NM_011708 & GCTTGAACTGTTTGACGGAGAGG & TGACCCAGCAGCAGGATGAC & $\begin{array}{l}\text { (Wang H et al. } \\
2005)\end{array}$ \\
\hline PECAM1 & NM_008816 & TCCCTGGGAGGTCGTCCAT & GAACAAGGCAGCGGGGTTTA & $\begin{array}{l}\text { (Wang H et al. } \\
2005)\end{array}$ \\
\hline VE-cadherin & X83930 & TCCTCTGCATCCTCACTATCACA & GTAAGTGACCAACTGCTCGTGAAT & $\begin{array}{l}\text { (Wang H et al. } \\
2005)\end{array}$ \\
\hline ZO-1 & NM_009386.2 & GGAGCTACGCTTGCCACACT & GGTCAATCAGGACAGAAACACAGT & (Li et al. 2010) \\
\hline OCLD & NM_008756.2 & ATCCTGTCTATGCTCATTATTGTG & CTGCTCTTGGGTCTGTATATCC & $\begin{array}{l}\text { (Wang et al. } \\
2006)\end{array}$ \\
\hline CLD5 & NM_013805 & TAAGGCACGGGTAGCACTCA & GCCCAGCTCGTACTTCTGTG & (Li et al. 2010) \\
\hline eNOS & NM_008713 & CACCAGGAAGAAGACCTTTAAGGA & CACACGCTTCGCCATCAC & $\begin{array}{l}\text { (Ferrer et al. } \\
2007)\end{array}$ \\
\hline ET-1 & NM_010104.3 & TTCCCGTGATCTTCTCTCTGCT & TCTGCTTGGCAGAAATTCCA & $\begin{array}{l}\text { (Uchide et al. } \\
2001)\end{array}$ \\
\hline COX-2 & NM_011198.3 & TTCAAAAGAAGTGCTGGAAAAGGT & GATCATCTCTACCTGAGTGTCTTT & $\begin{array}{l}\text { (Persaud et al. } \\
\text { 2004) }\end{array}$ \\
\hline GAPDH & M32599 & CGTGCCGCCTGGAGAAACC & TGGAAGAGTGGGAGTTGCTGTTG & $\begin{array}{l}\text { (Wang H et al. } \\
\text { 2005) }\end{array}$ \\
\hline
\end{tabular}

